\title{
Hydrogen Recovery from Hydrogen-Methane Gas Mixture Using Coffee Grounds Based Activated Carbon Bioadsorbent
}

\author{
Mahmud Sudibandriyo ${ }^{1 *}$, Faracitra Kusumadewi ${ }^{1}$ \\ ${ }^{1}$ Department of Chemical Engineering, Faculty of Engineering, Universitas Indonesia, Kampus UI-Depok, Jawa Barat \\ 16424, Indonesia
}

\begin{abstract}
Hydrogen recovery from off-gas of hydrocracking unit by adsorption is one of the process that could increase the efficiency processes of refinery unit. The purpose of this research is to make coffee grounds based activated carbon bioadsorbent that will be used in hydrogen recovery proses. The carbon was prepared by chemical activation using $\mathrm{ZnCl}_{2}$ at temperature $600^{\circ} \mathrm{C}$. The surface area of produced activated carbon was measured using BET and lodine number, while its surface morphology and composition were characterized using SEM-EDX. The adsorption capacity of activated carbon and its selectivity will be tested using hydrogen-methane gas mixture. The test was carried out on pure methane and hydrogen gas at $20^{\circ} \mathrm{C}$ and a mixture of $\mathrm{CH}_{4} / \mathrm{H}_{2}$ (mole ratio: $4: 1$ ) at $10^{\circ} \mathrm{C}, 20^{\circ} \mathrm{C}$ and $30^{\circ} \mathrm{C}$ and pressures from 1 to 6 bars. The results of this study show that the activated carbon can be successfully produced having the specific surface area of $728.07 \mathrm{~m}^{2} / \mathrm{g}$ and the iodine number of $2160 \mathrm{mg} / \mathrm{g}$. The result shows that the adsorption of pure $\mathrm{CH}_{4}$ gas at the same pressure was 2.4 times greater than pure $\mathrm{H}_{2}$. The adsorption test indicates that the produced activated carbon might be used for hydrogen/methane separation.
\end{abstract}

\section{Introduction}

Hydrogen is one of the main intermediate products largely utilized in oil and petrochemical industries. Its usage has been constantly growing in modern refineries, chemical, and petrochemical complexes in order to treat heavier oil feedstock [1]. Generally, in refineries or petrochemical complexes, the off-gas streams contain a considerable amount of hydrogen, which are mostly incinerated in refinery flares as a waste gas [2]. Therefore, the utilization of hydrogen from off-gas can increase process efficiency and reduce production costs. The off-gas produced in refinery unit consists of carbon dioxide, hydrogen, methane, and ethane. Adsorption would be the most suitable technology due to its ability to release either $\mathrm{CH}_{4}$ or $\mathrm{CO}_{2}$ and requires lower energy compared to other technologies [3].

One of the key factor that determines the adsorption's process is the adsorbent's characteristic, such as purity, structure, and pore distribution of adsorbent that will affect the surface area and volume of adsorbent. Most commonly used adsorbent is activated carbon, silica gel, alumina, resin, and zeolite due to their high adsorption capacity [4]. Among those adsorbents, activated carbon is the most used adsorbent because it is mainly composed of a carbonaceous material with a high surface area and porous structures. Although it is an excellent adsorbent, it is also very expensive for adsorption. The price of commercial activated carbon in the market is normally from about one thousand dollars to three thousand dollars per ton. Thus, there is a growing demand to find activated carbon with relatively efficient, low cost, and easily available raw material. Generally, activated carbon raw materials are an agricultural waste with lignocellulose and carbon content. Coffee ground is one of the potential activated carbon material due to its availability and cheap price. Based on previous study, coffee ground consists of $47.8 \%-58.9 \%$ carbon, $1.9-2.3 \%$ nitrogen, $0.43-1.6 \%$ ash, and $8.6 \%$ cellulose [5].

In the last years, the instant coffee industry has experienced a constant growth as instant coffee has become one of the most popular kinds of coffee drunk by millions of people around the world. As a consequence, large amounts of coffee grounds, which are the solid residues obtained during the processing of coffee powder with hot water or steam to prepare instant coffee, have been generated worldwide (in order of 6 million tons per year) [6].

Corresponding author: msudib@che.ui.ac.id 
The aim of this study is to get coffee grounds based activated carbon's characterization such as its surface area, pores volume, and morphology and to evaluate coffee grounds based activated carbon ability to adsorb $\mathrm{CH}_{4}$ from $\mathrm{CH}_{4} / \mathrm{H}_{2}$ mixture in isothermal conditions. This study expected to provide a recommendation of the effectiveness of the coffee grounds used as potential adsorbents' raw material that could be widely produced.

\section{Experimental Methods}

This study consists of three parts, which are the preparation of the activated carbon, adsorbent characterization, and the adsorption test. Adsorbent characterization was done with BET analysis, SEMEDX analysis, and Iodine number. The performance of produced activated carbon is tested on the adsorption of pure hydrogen, pure methane, and gas mixture at $20^{\circ} \mathrm{C}$, and it is also tested to a gas mixture of methane and hydrogen in isothermal condition at $10^{\circ} \mathrm{C}, 20^{\circ} \mathrm{C}$, and $30^{\circ} \mathrm{C}$ with the pressures range of $1-6$ bars.

\subsection{Materials}

The robusta coffee residues as raw material were collected from Starbucks Coffee Shop. All gases used in this study were high purity $(99.99 \%)$. Deionized water was used to prepare $\mathrm{ZnCl}_{2}$ and $\mathrm{HCl}$ solutions as well as for washing purpose.

\subsection{Preparation of Activated Carbon}

Coffee grounds were first washed with deionized water to remove impurities and then dried at $100^{\circ} \mathrm{C}$ for 24 hours. The samples were then crushed and sieved to a particle size of 60 mesh. Afterward, the coffee residues are impregnated with the $\mathrm{ZnCl}_{2}$ solution with $1 \mathrm{M}$ concentration with ratio 1 gram activated carbon: $10 \mathrm{~mL}$ $\mathrm{ZnCl}_{2}$ solution. The mixture was mixed for 1 hour at room temperature using a hot plate magnetic stirrer and then dried at $110^{\circ} \mathrm{C}$.

The dried samples were activated for $1 \mathrm{~h}$ at $600^{\circ} \mathrm{C}$ in a pyrolysis reactor under a nitrogen flow of $150 \mathrm{~mL} / \mathrm{min}$. The chemical impregnation used temperature of $600^{\circ} \mathrm{C}$ to obtain optimal surface area [7]. The weight losses due to activation were determined. The activated carbon was thoroughly washed with deionized water and soaked in $0.1 \mathrm{M}$ hydrochloric acid solution for 30 minutes in order to remove the residual zinc from the pores of the carbons. Afterward, the activated carbon was washed again using hot deionized water until the $\mathrm{pH}$ of 6 has been reached and dried in the oven at $110^{\circ} \mathrm{C}$. The dried activated carbon was crushed and sieved to a particle size of 60 mesh.

\subsection{Characterization of Activated Carbon}

The purpose of characterization is to determine the specific surface area, pore volume, morphology, and composition of activated carbon from coffee grounds.
The specific surface area was calculated with the BET method using 0.3 gram of activated carbon samples. Iodine characterization was done to determine the pore volume. A pore volume determined by the amount of adsorbed iodine per gram activated carbon (mg iodine/g activated carbon). 0.1 gram sample was stirred and then heated with $10 \mathrm{~mL}$ of iodine solution for 1 hour. Afterward, $5 \mathrm{~mL}$ of the mixed solution was titrated by $\mathrm{Na}_{2} \mathrm{SO}_{3}$. The volume of $\mathrm{Na}_{2} \mathrm{SO}_{3}$ used for titration then was inputted to iodine number calculation. Meanwhile, morphology and composition of activated carbon were determined using the SEM-EDX method. The purpose of SEM-EDX characterization is to determine whether produced activated carbon has enough pores and to get the composition of produced carbon.

\subsection{Isothermal Adsorption Test}

The adsorption process can be done with several measuring methods, of which one of these is volumetric method. Volumetric methods measure adsorption capacity and ability by using pressure change per hour at a constant temperature. This method of measurement is known as isothermal adsorption. The volumetric method is used in the methane installation, due to the similarity of its parameters with a methane adsorption testing device [8]. The isothermal adsorption experiment was performed based on the mass balance principle, which employs precise measurement of pressure, volumes, and temperatures. The tool used for the adsorption test assembled as in Fig 1. These tools consist of a dozing cylinder, a sampling cylinder, and pressure transducers. The sampling cylinder was fully filled with some amounts of sample. The mass of the sample within the sampling cylinder is determined. The volume void, $V_{\text {void }}$, in the sampling cylinder was determined by injecting some amounts of inert gas (Helium) into sampling cylinder through dozing cylinder by opening valve 2 while valve 1 and 3 stay closed until the volume of helium in sampling cylinder reached a certain pressure.

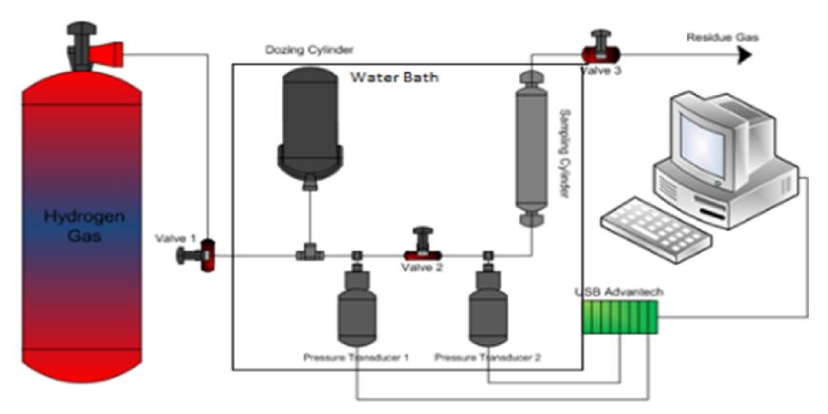

Fig. 1. Schematic Diagram of the Adsorption Test Apparatus [9]

This experiment used Helium as inert gas because helium is not significantly adsorbed. Therefore, the volume void can be determined by measuring temperatures, pressures, and the amount of injected 
helium into the sampling cylinder. Helium is injected several times with different pressure to determine the data consistency based on the following.

$$
V_{\text {void }}=\frac{n_{i} Z_{H e, S C} R T_{S C}}{P_{S C}}
$$

While the amount of helium injected into the sampling cylinder, $n_{i}$, was determined by the equation below

$$
n_{i=}\left[\left(\frac{P_{i}}{Z_{H e, i} R T_{i}}-\frac{P_{f}}{Z_{H e, f} R T_{f}}\right) V_{D C}\right]
$$

where $\mathrm{V}_{\mathrm{DC}}$ represents the volume of dozing cylinder, $P_{i}$ and $P_{f}$ are the initial and final pressure of the dozing cylinder respectively, while $\mathrm{R}$ is gas constant and $Z_{\mathrm{He}}$ is the compressibility factor of helium gas injected at different pressures.

The adsorption test was done with the similar method with three different gasses, which are pure hydrogen, pure methane, and $\mathrm{CH}_{4} / \mathrm{H}_{2}$ mixture. The $\mathrm{CH}_{4} / \mathrm{H}_{2}$ mixture was made with ratio 2:8. To determine the amount of adsorbed gas in the sampling cylinder, $n_{i}$, was calculated with Equation 2. The remaining gas presence in the sampling cylinder, $n_{u \text { nads }}$ in the equilibrium bulk phase is calculated with Equation 3

$$
n_{u \text { nads }}=\left(\frac{P V_{\text {void }}}{Z_{\text {gas }} R T}\right)_{c e l l}
$$

where $P$ is the pressure when the equilibrium reached in the sampling cylinder and $V_{\text {void }}$ from Equation 1. The equilibrium reached 30 minutes after the injection process. The amount of adsorbed gas, $n_{a d s}$, was calculated with Equation 4.

$$
n_{a d s}=n_{i n j}-n_{u \text { nads }}
$$

For multicomponent adsorption, the equation is modified using mol fraction of gas injected and mol fraction of unadsorbed gas as follows.

$$
n_{a d s}=n_{\text {inj }} y_{i, i n j}-n_{u \text { nads }} y_{i, u \text { nads }}
$$

Where $y_{i, i n j}$ is the initial composition of gas mixture while $y_{i, u \text { nads }}$ were determined using GC-TCD analysis. Those steps were repeated with pressure $1-6$ bars sequentially for each gas.

\subsection{Modeling}

The result of the adsorption test is represented with Langmuir isotherm adsorption model. Mol Gibbs adsorption, $n_{a d s}$, was calculated for every adsorption pressure. The Langmuir constant, $b$, and maximum adsorption capacity, $n_{\text {maks }}$ were guessed. Both constant will be used in Equation 6

$$
n_{a d s}^{a b s}=n_{\max } \frac{b P}{1+b P}
$$

where $P$ is pressure in the sampling cylinder.

Afterward, \%AAD (absolute average deviation) is determined with Gibbs mol adsorption $\left(n_{\text {model }}\right)$ and the amount of Gibbs mol adsorption from experiment $\left(n_{\text {exp }}\right)$. The \%AAD were calculated to determine the error in the experiment with Equation 7.

$$
\% \mathrm{AAD}=\frac{\sum_{i}^{N}\left|\frac{n_{\mathrm{exp}}-n_{\text {nodel }}}{n_{\exp }}\right| x 100}{N}
$$

\section{Result and Discussion}

In this section, the characterization of activated carbon obtained and its performance of gas adsorption will be discussed further. Moreover, the Langmuir adsorption model calculation will also be discussed further to determine whether the gas adsorption result fits the Langmuir isothermal model

\subsection{Adsorbent Preparation and Characterization}

The yield of activated carbon obtained was calculated to determine the mass loss of activated carbon during the activation process. The yield of activated carbon obtained shown in Table 1.

Table 1. The yield of Activated Carbon Obtained

\begin{tabular}{|c|c|c|c|}
\hline No. & $\begin{array}{c}\text { Carbon initial } \\
\text { mass (gram) }\end{array}$ & $\begin{array}{c}\text { Activated carbon } \\
\text { mass after the } \\
\text { activation process } \\
\text { (gram) }\end{array}$ & Yield (\%) \\
\hline 1 & 25 & 7.7 & 35.6 \\
\hline 2 & 20 & 6.9 & 34.5 \\
\hline 3 & 25 & 11.0 & 44 \\
\hline \multicolumn{3}{|c|}{ Average yield } & 38.03 \\
\hline
\end{tabular}

Based on Table 1, the average yield of activated carbon obtained is $38.03 \%$. A similar study by Alnassar with higher temperature and higher concentration of $\mathrm{ZnCl}_{2}$ as activating agent showed lower yields of the product [10]. The higher yield of product achieved in this study indicates higher amount of inorganics oxides in the activated carbon obtained during the activation process [10]. At lower concentration, $\mathrm{ZnCl}_{2}$ reacts with $\mathrm{H}$ and $\mathrm{O}$ on the surface of activated carbon and forms $\mathrm{H}_{2} \mathrm{O}$ and $\mathrm{H}_{2}$, rather than burning away the carbon $(\mathrm{CO}$ and $\mathrm{CO}_{2}$ ), which leads to higher yields [11]. In addition, higher temperature also accelerates dehydration reaction to happen. Therefore, dehydration reaction will evaporate water contain and $\mathrm{ZnCl}_{2}$ in sample surface area.

The result of the specific surface area using the BET method is $728.07 \mathrm{~m}^{2} / \mathrm{g}$. A previous study by Haris with similar raw material and activating agent but lower 
activation temperature shows a lower specific surface area [12]. Higher activation temperature in this study accelerates the volatilization and decomposition of the sample, which leads to an increase in the specific surface area and enhanced pore development [13]. Meanwhile, the result of iodine number is $2160 \mathrm{mg} / \mathrm{g}$. The result shows that produced activated carbon meets the characteristics of commercial activated carbon because it has iodine number greater than $200 \mathrm{mg} / \mathrm{g}$, based on Indonesian National Standard.

The SEM-EDX characterization shows the magnification of produced activated carbon pores and its composition. Based on the result, the produced activated carbon consists of $99.64 \%$ carbon, $0.23 \%$ oxygen, $0.08 \%$ sulphur, $0.03 \%$ chloride, $0.02 \%$ zinc. The morphology using SEM with magnifications of 1000 times and 1500 times shown in Fig 2 and Fig 3

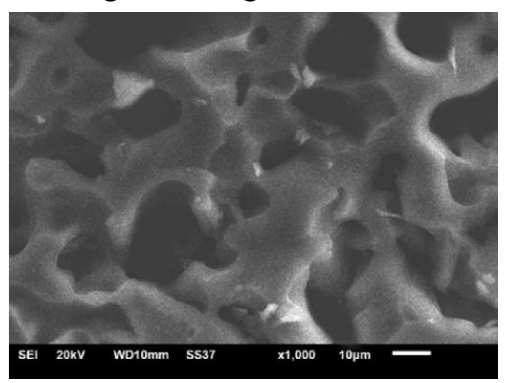

Fig. 2. SEM-EDX 1000x Magnified

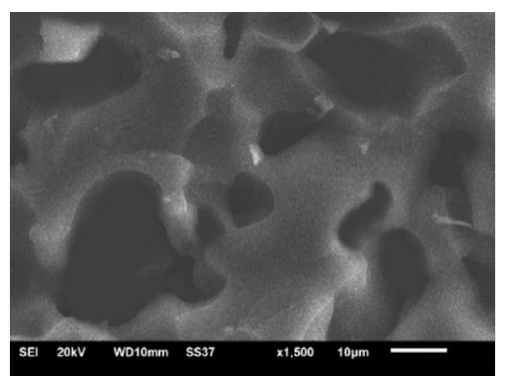

Fig. 3. SEM-EDX 1500x Magnified

According to the SEM images, the produced activated carbon has a highly porous structure which appeared to have a rough texture with heterogeneous surface structure. The white spares on the surface prove the existence of zinc salt residues.

The result of coffee grounds activated carbon's characterization is compared to commercial carbon and the result can be seen in Table 2 .

Table 2. Comparison of Characteristics between Commercial and Coffee Grounds Activated Carbon

\begin{tabular}{|c|c|c|}
\hline Characteristics & $\begin{array}{c}\text { Commercial } \\
\text { Activated Carbon }\end{array}$ & $\begin{array}{c}\text { Coffee Grounds } \\
\text { Activated Carbon }\end{array}$ \\
\hline Surface Area & $300-2500 \mathrm{~m}^{2} / \mathrm{g}$ & $728.07 \mathrm{~m}^{2} / \mathrm{g}$ \\
\hline Iod Number & Min. $750 \mathrm{mg} / \mathrm{g}$ & $2160 \mathrm{mg} / \mathrm{g}$ \\
\hline Carbon Contain & Min. $65 \%$ & $99.94 \%$ \\
\hline
\end{tabular}

Therefore, we can conclude that activated carbon that has been produced in this research can be considered as commercial activated carbon.

\subsection{Adsorption Test and Modelling}

Volume void of activated carbon that has been determined with 4.7 gram activated carbon in the sampling cylinder is $3.26 \mathrm{~mL}$. The void volume of the activated carbon in the sampling cylinder calculated is 3 $\mathrm{ml}$. It is the average of six trials that have been carried out at $1-6$ bars.

Table 3. Performance Comparison of Coffee Grounds and Palm Shell Bases Activated Carbon

\begin{tabular}{|c|c|c|}
\hline \multirow{4}{*}{ Raw Material } & Pressure (bar) & $\begin{array}{c}\text { Adsorption } \\
\text { (mmol/g AC) }\end{array}$ \\
\hline \multirow{4}{*}{$\begin{array}{c}\text { Coffee } \\
\text { Grounds }\end{array}$} & 1.06 & 0.062 \\
\cline { 2 - 3 } & 2.05 & 0.118 \\
\cline { 2 - 3 } & 3.25 & 0.177 \\
\cline { 2 - 3 } & 4.04 & 0.234 \\
\cline { 2 - 3 } & 5.20 & 0.295 \\
\hline \multirow{4}{*}{ Palm Shell } & 6.25 & 0.335 \\
\cline { 2 - 3 } & 1.30 & 0.041 \\
\cline { 2 - 3 } & 2.10 & 0.076 \\
\cline { 2 - 3 } & 3.00 & 0.109 \\
\cline { 2 - 3 } & 4.00 & 0.120 \\
\cline { 2 - 3 } & 5.10 & 0.159 \\
\hline
\end{tabular}

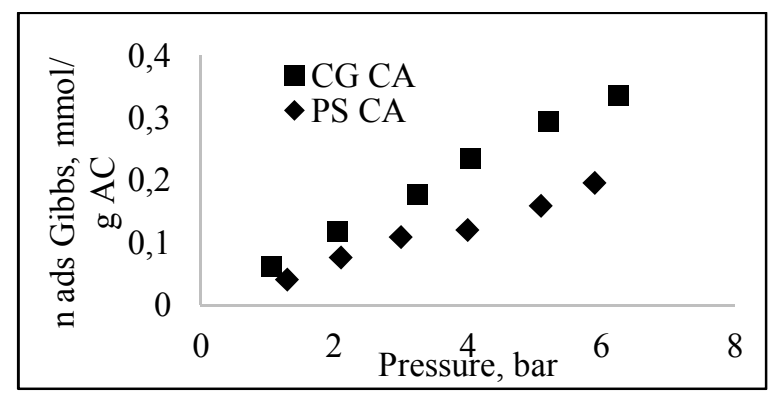

Fig. 4. Adsorption of $\mathrm{CH}_{4} / \mathrm{H}_{2}$ at $20^{\circ} \mathrm{C}$ on Palm Shell and Coffee Grounds Activated Carbon

Fig. 4. and Table 3 show the performance comparison between produced coffee grounds based activated carbon and palm shell based activated carbon obtained from the previous research carried out by Putri and Sudibandriyo [9]. It is shown that the adsorption of gas mixture performed with coffee ground based activated carbon is higher than palm oil based activated carbon. It is because a higher surface area allows activated carbon to bind more gas molecules.

Table 4. Adsorption Result of $\mathrm{CH}_{4}, \mathrm{H}_{2}$, and $\mathrm{CH}_{4}(21.5 \%) / \mathrm{H}_{2}$ at $20^{\circ} \mathrm{C}$ 


\begin{tabular}{|c|c|c|}
\hline Adsorbate & Pressure (bar) & $\begin{array}{c}\text { Adsorption } \\
\text { (mmol/g AC) }\end{array}$ \\
\hline \multirow{6}{*}{$\mathrm{CH}_{4}$} & 1.07 & 0.088 \\
\hline & 2.15 & 0.170 \\
\hline & 3.09 & 0.233 \\
\hline & 4.29 & 0.305 \\
\hline & 5.47 & 0.380 \\
\hline & 6.36 & 0.425 \\
\hline \multirow{6}{*}{$\mathrm{H}_{2}$} & 1.18 & 0.040 \\
\hline & 2.23 & 0.071 \\
\hline & 3.26 & 0.102 \\
\hline & 4.20 & 0.127 \\
\hline & 5.47 & 0.163 \\
\hline & 6.37 & 0.181 \\
\hline \multirow{6}{*}{$\mathrm{CH}_{4}(21.5 \%) / \mathrm{H}_{2}$} & 1.05 & 0,048 \\
\hline & 2.07 & 0,106 \\
\hline & 3.25 & 0.165 \\
\hline & 4.35 & 0.203 \\
\hline & 5.32 & 0.232 \\
\hline & 6.05 & 0.249 \\
\hline
\end{tabular}

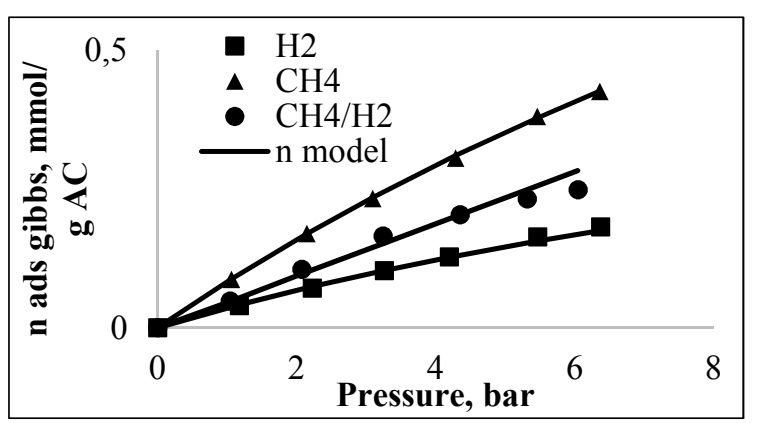

Fig. 5. Adsorption of $\mathrm{CH}_{4}, \mathrm{H}_{2}$, and $\mathrm{CH}_{4}(21.5 \%) / \mathrm{H}_{2}$ at $20^{\circ} \mathrm{C}$

Fig 5 and Table 4 shows the result of adsorption of pure methane, pure hydrogen, and $\mathrm{CH}_{4} / \mathrm{H}_{2}$ mixture in isotherm condition at $20^{\circ} \mathrm{C}$. The optimal adsorption for pure $\mathrm{CH}_{4}$ gas reaches $0.425 \mathrm{mmol} / \mathrm{g}$, while for the $\mathrm{CH}_{4} / \mathrm{H}_{2}$ mixture is $0.249 \mathrm{mmol} / \mathrm{g}$ and for pure $\mathrm{H}_{2}$ reaches $0.181 \mathrm{mmol} / \mathrm{g}$. This result shows that the adsorption of pure $\mathrm{CH}_{4}$ is higher than $\mathrm{CH}_{4} / \mathrm{H}_{2}$ mixture and pure $\mathrm{H}_{2}$. This means that the adsorption of pure $\mathrm{CH}_{4}$ gas at the same pressure is 1.71 times greater than $\mathrm{CH}_{4}(21.5 \%) / \mathrm{H}_{2}$ mixture. Meanwhile, the adsorption of pure $\mathrm{CH}_{4}$ gas at the same pressure is 2.4 times greater than pure $\mathrm{H}_{2}$. Evaluation of composition in unadsorbed $\mathrm{CH}_{4}$ gas also shows that activated carbon adsorbs most of $\mathrm{CH}_{4}$ injected. These facts indicate that produced activated carbon might be used for hydrogen/methane separation. Pure $\mathrm{CH}_{4}$ gas is the most adsorbed than any other gas because of its molecular size. The molecular size of $\mathrm{CH}_{4}$ and $\mathrm{H}_{2}$ is $3.8 \AA$ and $2.8 \AA$ respectively, while the mean pore size of activated carbon diameter is $16 \AA$. This cause the hydrogen molecules do not stay on the surface of the adsorbent but tend to stay in the bulk phase [14].
Table 5. Adsorption Results of $\mathrm{CH}_{4}(21.5 \%) / \mathrm{H}_{2}$ at $10^{\circ} \mathrm{C}$ and $30^{\circ} \mathrm{C}$

\begin{tabular}{|c|c|c|}
\hline Temperature $\left({ }^{\circ} \mathbf{C}\right)$ & $\begin{array}{c}\text { Pressure } \\
(\mathbf{b a r})\end{array}$ & $\begin{array}{c}\text { n Gibbs Ads } \\
(\mathbf{m m o l} / \mathbf{g} \text { AC) }\end{array}$ \\
\hline \multirow{4}{*}{10} & 1.1 & 0.073 \\
\cline { 2 - 3 } & 2.35 & 0.142 \\
\cline { 2 - 3 } & 3.3 & 0.207 \\
\cline { 2 - 3 } & 4.19 & 0.228 \\
\cline { 2 - 3 } & 5.10 & 0.248 \\
\cline { 2 - 3 } & 6.10 & 0.321 \\
\hline \multirow{4}{*}{30} & 1.08 & 0.037 \\
\cline { 2 - 3 } & 2.15 & 0.069 \\
\cline { 2 - 3 } & 3.23 & 0.108 \\
\cline { 2 - 3 } & 44.15 & 0.134 \\
\cline { 2 - 3 } & 5.10 & 0.193 \\
\cline { 2 - 3 } & 6.29 & 0.237 \\
\hline
\end{tabular}

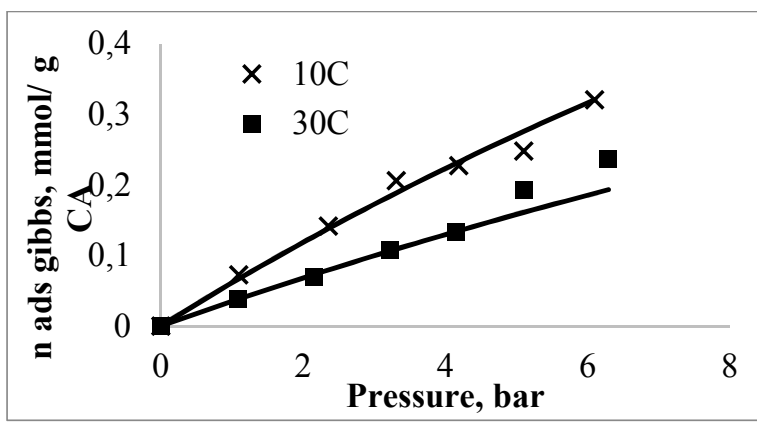

Fig. 6. Adsorption of $\mathrm{CH}_{4}(21.5 \%) / \mathrm{H}_{2}$ at $10^{\circ} \mathrm{C}$ and $30^{\circ} \mathrm{C}$

Fig 6 and Table 5 shows the result of $\mathrm{CH}_{4}(21.5 \%) / \mathrm{H}_{2}$ adsorption of coffee based activated carbon at isothermal conditions of 10 and $30^{\circ} \mathrm{C}$. Based on the table, the optimal adsorption was obtained at an isothermal condition at $10^{\circ} \mathrm{C}$ with the pressure of 6 bars. The amount of adsorbed gas is $0.321 \mathrm{mmol} / \mathrm{g}$. This amount is 1.3 times higher than the adsorption at $30^{\circ} \mathrm{C}$ at the same pressure. This result fits the Le Chatelier principle that states the exothermic reaction would favor lower temperature.

The results of isotherm adsorption obtained from this study presented with a Langmuir isotherm model that described physical interactions between adsorbate and adsorbent molecules as shown in Fig. 5 and Fig. 6.

Table 6. Langmuir Parameters of Methane and Hydrogen Isothermal Adsorption

\begin{tabular}{|c|c|c|c|}
\hline Feed & $\boldsymbol{n}_{\max }$ & $\boldsymbol{b} \times \mathbf{1 0}^{\mathbf{2}}$ & \%AAD \\
\hline $\mathrm{CH}_{4}$ & 1.9019 & 4.53 & 0.52 \\
\hline $\mathrm{H}_{2}$ & 0.6619 & 5.63 & 2.66 \\
\hline
\end{tabular}

Table 7. Langmuir Parameters of $\mathrm{CH}_{4}(21.5 \%) / \mathrm{H}_{2}$ Adsorption at $10^{\circ} \mathrm{C}, 20^{\circ} \mathrm{C}$ and $30^{\circ} \mathrm{C}$ 


\begin{tabular}{|c|c|c|c|}
\hline Temp $\left({ }^{\mathbf{0}} \mathbf{C}\right)$ & $\boldsymbol{n}_{\text {maks }}$ & $\boldsymbol{b} \times \mathbf{x 1 0}^{\mathbf{2}}$ & \%AAD \\
\hline 10 & 1.89 & 3.35 & 5.50 \\
\hline 20 & 1.51 & 3.10 & 6.33 \\
\hline 30 & 1.35 & 2.65 & 7.23 \\
\hline
\end{tabular}

Based on Table 6 and Table 7, it can be seen that the result of pure gas and gas mixture isotherm adsorption test in this study fits Langmuir isothermal adsorption model. This is also supported by the result of \%AAD on the adsorption, which is less than $10 \%$. The value of $\% \mathrm{AAD}$ increase with the increase in temperature because the gas adsorption on the adsorbent will be lower for higher temperature. Therefore, it can be concluded that the suitable Langmuir Model is applied to pure gas and gas mixture in this study.

\section{Conclusion}

This study was obtained coffee grounds based activated carbon with a BET surface area of $728.07 \mathrm{~m}^{2} / \mathrm{g}$ and an iodine number of $2160 \mathrm{mg} / \mathrm{g}$. The isotherm adsorption test shows that methane adsorption capacity was the highest then followed by adsorption of $\mathrm{CH}_{4} / \mathrm{H}_{2}$ mixture and pure hydrogen respectively. The adsorption of pure $\mathrm{CH}_{4}$ gas at the same pressure is 2.4 times greater than pure $\mathrm{H}_{2}$. Thus, the coffee grounds based activated carbon obtained in this study can be used as bioadsorbent in hydrogen separation from $\mathrm{CH}_{4} / \mathrm{H}_{2}$ mixture. The activated carbon produced in this experiment might also be applied in industrial scale, considering the operation condition in hydrogen recovery unit.

The author would like to thank all parties that have supported this study, especially Universitas Indonesia via Grant of International Publication Indexed for Thesis of UI's Students or known as PITTA 2018 Grant No: 2473/UN2. R3.1/HKP.05.00/2018.

\section{References}

1. S. Faraji, R. Sotudeh-Gharebagh, and N. Mostoufi. Hydrogen Recovery from Refinery Off-gasses, Journal of Applied Science 5, 459-464 (2005)

2. S. Ratan, P. Wentink. Cost Effective Hydrogen from Refinery Off-Gases, Proceedings of $4^{\text {th }}$ National Rubber Conference, 131-137 (2001)

3. M. Shafeeyan, W. Daud, A. Houshmand, A. Shamiri. A Review on Surface Modification of Activated Carbon for Carbon Dioxide Adsorption, Journal of Analytical and Applied Pyrolysis 89, 143-151 (2010)

4. G. Kyzas. Commercial Coffee Wastes as Materials for Adsorption of Heavy Metals from Aqueous Solutions, Materials 5(10), 1826-1840 (2012)

5. N. Caetano, V. Silva, T. Mata. Valorization of Coffee Grounds for Biodiesel Production, Chemical Engineering Transactions 26, 267-272 (2012)

6. S. Mussatto, E. Machado, S. Martins, J. Teixeira. Production, Composition, and Application of Coffee and Its Industrial Residues, Food Bioprocess Technol 4, 661-672 (2011)

7. D. Cherik, K. Louhab. Preparation of Microporous Activated Carbon from Dates Stones by Chemical Activation Using Zinc Chloride, Energy Sources, Part A: Recovery, Utilization, and Environmental Effects 39:18, 1935-1941 (2017)

8. Alhamid, M.I., Nasruddin, Senoadi, Perdana, M.B., Kartiko. Effect of Methane Gas Flow Rate on Adsorption Capacity and Temperature Distribution of Activated., International Journal of Technology. Volume 6(4), 584-593 (2015)

9. S. N. Putri, M. Sudibandriyo, Hydrogen Recovery from Hydrogen-Methane Gas Mixture Utilized by Palm Shell Bioadsorbent Activated Carbon, Proceeding of the $15^{\text {th }}$ International Conference on QIR, ISSN 1411-1284, (2017)

10.F. Alnassar. Preparation and Characterization of Activated Carbon from Coffee Wastes, (2015)

11. T. Liu. Development of Mesoporous Structure and High Adsorption Capacity of Biomass-Based Activated Carbon by Phosphoric Acid and Zinc Chloride Activation, Chem. Eng. J. 158(2), 129 -142 (2010)

12. F. Haris. Rekayasa Adsorben Masker Karbon Aktif dari Limbah Ampas Kopi, (2016)

13.S. Yorgun \& D. Yildiz. Preparation and Characterization of Activated Carbons from Paulownia Wood by Chemical Activation with $\mathrm{H}_{3} \mathrm{PO}_{4}$, Journal of Taiwan Institute of Chemical Engineers, 1 - 10 (2015)

14. M. Sudibandriyo, IJET, 11, 79 - 82 (2011) 